\title{
The Influence of FGD Gypsum Fabricated from Limestone Sludge on Cement Properties
}

\author{
Sung Kwan Seo****, Yong Sik Chu**, Kwang Bo Shim**, Jong Kyu Lee*, and Hun Song* \\ *Energy and Environmental Division, Korea Institute of Ceramic Engineering and Technology, Jinju 52851, Korea \\ **Division of Materials Science and Engineering, Hanyang University, Seoul 04763, Korea \\ (Received July 11, 2016; Revised September 28, 2016; Accepted October 7, 2016)
}

\begin{abstract}
For the purpose of reducing the amount of limestone, which is used as a desulfurization agent to absorbing $\mathrm{SO}_{\mathrm{x}}$ gas in thermal power plants, and to recycle limestone sludge generated from a steel mill, limestone sludge was utilized as a desulfurization agent. In this study, cement, made of flue gas desulfurization (FGD) gypsum obtained in a desulfurization process using limestone sludge, was manufactured then, experiments were conducted to identify the physical properties of the paste and mortar using the cement. The results of the crystal phase and microstructure analyses showed that the hydration product of the manufactured cement was similar to that of ordinary Portland cement. No significant decline of workability or compressive strength was observed for any of the specimens. From the results of the experiment, it was determined that FGD gypsum manufactured from limestone sludge did not influence the physical properties of the cement also, quality change did not occur with the use of limestone sludge in the flue gas desulfurization process.
\end{abstract}

Key words : FGD systems, Limestone sludge, FGD gypsum, Waste recycling, Mortar

\section{Introduction}

F lue Gas Desulfurization (FGD) technology is a technology for $\mathrm{SO}_{2}$ gas removal which was developed in the mid-20th century and has been used in thermal power plants to date. ${ }^{1,2)}$ FGD technology refers to a technology used to remove SOx contained in the exhaust gas after combustion, using principles such as absorption, adsorption, oxidation, and reduction. ${ }^{3)}$ In addition, FGD technology is largely divided into the dry method and wet method according to the moisture content of the desulfurization agent, and it is operated mainly by applying limestone-gypsum wet flue gas desulfurization by which gypsum $\left(\mathrm{CaSO}_{4} \cdot 2 \mathrm{H}_{2} \mathrm{O}\right)$ is obtained as a desulfurization byproduct. ${ }^{4)}$ In addition, gypsum obtained as a byproduct of the desulfurization process is called gypsum flue gas desulfurization gypsum (FGDG), and FGDG is mostly used in manufacturing gypsum boards.

The limestone used for limestone-gypsum wet flue gas desulfurization is high-purity limestone with the $\mathrm{CaCO}_{3}$ content of at least $93 \%$, and the purity of limestone is directly related to desulfurization efficiency and the quality of flue gas desulfurization gypsum. ${ }^{5)}$ However, the reserves of high-quality limestone are limited since it is used as a main or subsidiary material in cement manufacturers and steel mills. ${ }^{6)}$ Therefore, studies were performed to apply

${ }^{\dagger}$ Corresponding author : Yong Sik Chu

E-mail : yschu@kicet.re.kr

Tel : +82-55-792-2463 Fax : +82-55-792-2469 lime sludge to flue gas desulfurization in order to reduce the amount of limestone used as a desulfurizing agent in thermal power plants. ${ }^{7)}$ Limestone sludge is designated waste with the water content of $15 \%$ generated during the manufacture of $\mathrm{CaO}$ used as a subsidiary material in steel mills and it contains $90 \%$ or more $\mathrm{CaCO}_{3}$. If a desulfurization test is conducted after mixing limestone slurry and limestone sludge used in conventional desulfurization processes at a predetermined ratio, the desulfurization effect equal to that of conventional desulfurizing agents can be obtained. ${ }^{7}$

Thus, this study aimed to fabricate FGD gypsum by the field application of limestone sludge during the flue gas desulfurization process of a thermal power plant, and examine the changes in the performance of cement and cement mortar after applying the fabricated FGD gypsum to cement and cement mortar. Generally, gypsum is used to control the setting time of cement in a cement production process, and cement is produced by mixing it with cement clinker and then grinding the mixture. Therefore, in order to investigate the influence of the quality of FGD gypsum on the performance of cement when limestone sludge is used as a desulfurizing agent, cement was manufactured by mixing cement clinker and FGD gypsum at a specific ratio and grinding it. In addition, this study intended to analyze cement hydrates and examine the physical properties of cement and cement mortar using the manufactured cement.

\section{Experimental Procedure}

Limestone-gypsum wet flue gas desulfurization occurs 
through the reaction of limestone slurry used as a desulfurizing agent and $\mathrm{SO}_{2}$ gas in the absorber, and it can be represented by chemical equations as shown in the equations (1)(9) below.

$$
\begin{aligned}
& \text { specific reactions } \\
& \mathrm{SO}_{2}(\mathrm{~g})+\mathrm{H}_{2} \mathrm{O} \Leftrightarrow \mathrm{SO}_{2} \cdot \mathrm{H}_{2} \mathrm{O} \\
& \mathrm{SO}_{2} \cdot \mathrm{H}_{2} \mathrm{O} \Leftrightarrow \mathrm{H}^{+}+\mathrm{HSO}_{3}^{-} \\
& \mathrm{H}^{+}+\mathrm{CaCO}_{3} \Leftrightarrow \mathrm{Ca}^{2+}+\mathrm{HCO}_{3}^{-} \\
& \mathrm{Ca}^{2+}+\mathrm{HSO}_{3}^{-}+2 \mathrm{H}_{2} \mathrm{O} \Leftrightarrow \mathrm{CaSO}_{3} \cdot 2 \mathrm{H}_{2} \mathrm{O}+\mathrm{H}^{+} \\
& \mathrm{H}^{+}+\mathrm{HCO}_{3}^{-} \Leftrightarrow \mathrm{CO}_{2} \cdot \mathrm{H}_{2} \mathrm{O} \\
& \mathrm{CO}_{2} \cdot \mathrm{H}_{2} \mathrm{O} \Leftrightarrow \mathrm{CO}_{2}(\mathrm{~g})+\mathrm{H}_{2} \mathrm{O}
\end{aligned}
$$

$$
\begin{aligned}
& \text { overall reaction } \\
& \mathrm{CaCO}_{3}(\mathrm{~s})+\mathrm{H}_{2} \mathrm{O}+2 \mathrm{SO}_{2} \rightarrow \mathrm{Ca}^{2+}+2 \mathrm{HSO}_{3}^{-}+\mathrm{CO}_{2}(\mathrm{~g}) \\
& \mathrm{CaCO}_{3}(\mathrm{~s})+2 \mathrm{HSO}_{3}^{-}+\mathrm{Ca}^{2+} \rightarrow 2 \mathrm{CaSO}_{3}+\mathrm{CO}_{2}(\mathrm{~g})+\mathrm{H}_{2} \mathrm{O} \\
& \Rightarrow 2 \mathrm{CaCO}_{3}(\mathrm{~s})+2 \mathrm{SO}_{2} \rightarrow 2 \mathrm{CO}_{2}(\mathrm{~g})+2 \mathrm{CaSO}_{4}
\end{aligned}
$$

In order to examine the impact of the quality of FGD gypsum Fig. 1 on cement when FGD gypsum is produced by using limestone sludge in the flue gas desulfurization process, FGD gypsum samples produced before and after the addition of limestone sludge (one type produced before the addition of FGD gypsum(Bef.) and two types produced after the addition of FGD gypsum(Aft-1, Aft-2)) were obtained, and cement was manufactured(cement made with Bef:: Befc; cement made with Aft-1: Aftc-1; cement made with Aft-2: Aftc-2). The normal Portland cement clinker produced by $\mathrm{S}$ company, a domestic company, was obtained and used, and cement was made by mixing cement clinker and $5 \%$ of FGD gypsum, and then grinding the mixture with a vibration mill (WTVM, Woongbi Machinery, KOREA) for 35 minutes.

The fineness of the produced cement was measured with an air permeability apparatus(HJ-1105, Heungjin Testing Machine, KOREA) and the cement paste was made by setting the ratio of the $\mathrm{W} / \mathrm{C}$ (water/cement) at $35 \%$. The manufactured cement paste bed was water cured for 3 days, 7 days and 28 days in a constant temperature water bath with the temperature controlled to $21^{\circ} \mathrm{C}$, and then the analysis on cement hydrates was conducted. In order to analyze cement hydrates, the crystalline phase analysis was conducted with a X-ray diffractometer (D5005D, ZIEMENS, GERMANY) and microstructure observation was performed with a scanning electron microscope (SM300, TOPCON, JAPAN). In addition, for the analysis on physical properties of cement, the measurement of setting time was conducted with a Vicat apparatus (HJ-1110, Heungjin Testing Machine, KOREA) (KS L 5108), and the autoclave expan-

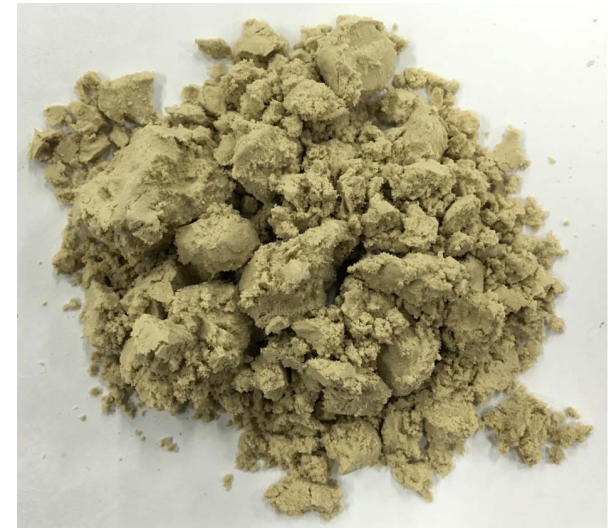

Fig. 1. Flue gas desulfurization gypsum (FGDG).

sion test was carried out (KS L 5107).

In addition, cement mortar manufacture test (W/C: $50 \%$ ) was carried out in order to examine the influence of the quality of the FGD gypsum fabricated from limestone sludge on compressive strength of cement mortar when limestone sludge is used in the flue gas desulfurization process. The specimen of cement mortar with the size of $40 \times 40 \times$ 160 (KS L ISO 679) was manufactured by measuring sand with controlled particle sizes and mixing water at the ratio of $250 \%$ and $50 \%$ of the cement weight, respectively, and then mixing them using a mixer for 4 minutes. The compressive strength of prepared specimens according to the material age was measured after water-curing them in a constant temperature water bath with the temperature controlled to $21^{\circ} \mathrm{C}$ for 3 days, 7 days and 28 days. The flow test was also carried out in accordance with "the testing method for compressive strength of hydraulic cement mortar (KS L 5105)" in order to analyze and evaluate the workability of the mortar according to the types of FGD gypsum samples.

\section{Results and Discussion}

Wet chemical analysis was performed to analyze the chemical composition of FGD gypsum fabricated by the application of limestone sludge to the flue gas desulfurization process, and the results are shown in Table 1. Looking at the results of chemical composition analysis, for $\mathrm{SO}_{3}$ which represents the purity of gypsum, the purity of FGD gypsum was similar in all the FGD gypsum types produced before and after applying limestone sludge or showed a slight tendency to increase.

The crystalline phases of FGD gypsum was analyzed using an X-ray diffractometer, and the results are shown in

Table 1. Chemical Composition of FGDG

(Unit : wt\%)

\begin{tabular}{ccccccccccc}
\hline & $\mathrm{SiO}_{2}$ & $\mathrm{Al}_{2} \mathrm{O}_{3}$ & $\mathrm{Fe}_{2} \mathrm{O}_{3}$ & $\mathrm{TiO}_{2}$ & $\mathrm{CaO}$ & $\mathrm{MgO}$ & $\mathrm{Na}_{2} \mathrm{O}$ & $\mathrm{K}_{2} \mathrm{O}$ & $\mathrm{SO}_{3}$ & Ig.loss \\
\hline Bef. & 0.21 & 0.28 & 0.23 & 0.01 & 35.6 & 0.52 & 0.05 & 0.52 & 42.9 & 19.5 \\
Aft-1 & 0.26 & 0.25 & 0.22 & 0.01 & 36.6 & 0.50 & 0.02 & 0.97 & 43.0 & 18.0 \\
Aft-2 & 0.25 & 0.36 & 0.13 & 0.01 & 36.9 & 0.51 & 0.13 & 0.60 & 43.7 & 17.3 \\
\hline
\end{tabular}




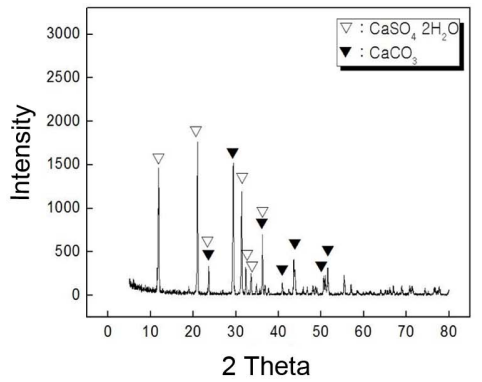

(a)Bef.

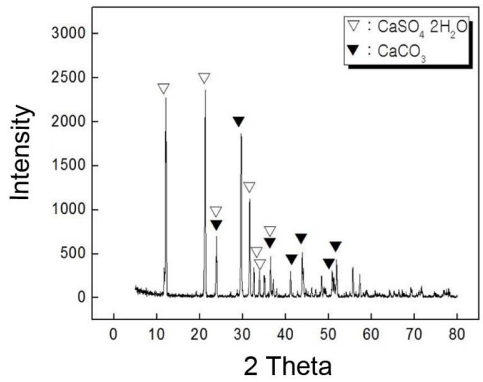

(b)Aft-1

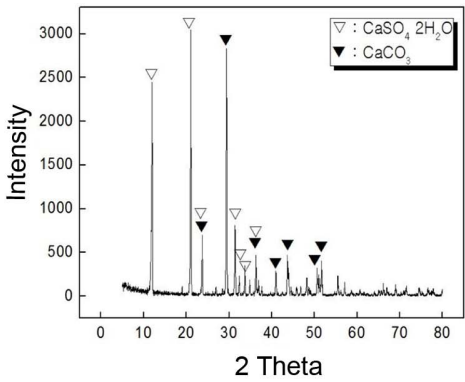

(c) Aft-2

Fig. 2. Comparison of XRD patterns with FGDG (a) produced before the addition of limestone sludge. (b) produced after the addition of limestone sludge at first sampling. (c) produced after the addition of limestone sludge at second sampling.

Fig. 2. As a result of X-ray diffraction analysis, all the FGD gypsum types produced before and after the addition of limestone sludge were found to be calcium sulfate dihydrate, and no differences in crystalline phases were observed between the FGD gypsum type produced before the addition of limestone sludge and the ones produced after the addition of limestone sludge. However, it was found that when limestone sludge was added, the peak intensity of calcium sulfate dihydrate was increased, and this result was thought to indicate that the purity of gypsum was increased with the use of limestone sludge as shown in the results of chemical composition analysis. Furthermore, the crystals of calcite $\left(\mathrm{CaCO}_{3}\right)$ were identified, and they were thought to be unreacted limestone crystals which did not react with $\mathrm{SO}_{2}$ gas in the absorber.

\subsection{Evaluation of physical properties of cement}

The fineness of cement was measured using an air-permeability apparatus in order to analyze and evaluate the physical properties of the cement manufactured, and the results are shown in Table 2. As a result of measuring the fineness of cement, the values of all the three types of cement were found to be $3,370 \mathrm{~cm}^{2} / \mathrm{g}$, and no differences in the fineness depending on the type of FGD gypsum were not observed.

After measurement of the fineness of cement was completed, the cement paste bed was prepared by fixing the W/ $\mathrm{C}$ at $35 \%$, and the analysis of cement hydrates was conducted after water curing it for 3 days, 7 days and 28 days in a constant temperature water bath with the temperature controlled to $21^{\circ} \mathrm{C}$. The analysis of crystalline phases was performed using an X-ray diffractometer for the analysis of cement hydrates, and the results of the analysis of crystalline phases according to the curing time are presented in Fig. 3.

Table 2. Fineness of Cement

\begin{tabular}{cc}
\hline & Fineness $\left(\mathrm{cm}^{2} / \mathrm{g}\right)$ \\
\hline Befc. & 3,370 \\
Aftc-1 & 3,370 \\
Aftc-2 & 3,370 \\
\hline
\end{tabular}

The results of the analysis of crystalline phases showed that Ettringite, C-S-H based hydrates and C-H based hydrates such as $\mathrm{Ca}(\mathrm{OH})_{2}$, which are common cement hydrates, were generated in all the specimens. However, for Aftc- 1 and Aftc-2 hydrates, they were found to exhibit slightly higher peak intensities than Befc hydrates, which was thought to be due to the content differences between gypsum types (Aft-1, Aft-2) as shown in the results of the chemical analysis above.

After completing the analysis of crystalline phases, the microstructure of the specimens was observed with a scanning electron microscope, and the results are shown in Fig. 4. Through the observation of the microstructure, it was possible to identify the crystals of Ettringite, $\mathrm{Ca}(\mathrm{OH})_{2}$, mono-sulphate, and C-S-H gel, which were identified in the analysis of crystalline phases of all the specimens.

Following the microstructure observation, the setting time and autoclave expansion were measured, using a Vicat apparatus and autoclave, and the results are shown in Table 3.

As shown in Table 2, normal consistency was found to be $23.8 \%, 23.7 \%$ and $23.8 \%$, respectively, and it was believed that the three types of cement showed almost no differences in normal consistency because there were no significant differences in the fineness and components of them. In addition, the setting time was similar in all the specimens, and the specimens also showed no significant differences in autoclave expansion $(0.08 \sim 0.10 \%)$. In other words, when FGD gypsum fabricated from limestone sludge was applied in the cement manufacture, no differences in the physical properties of cement were observed, and these results were thought to indicate that the application of limestone sludge led to no differences in the quality of FGD gypsum.

\subsection{Evaluation of physical properties of cement mortar}

The specimens of cement mortar were manufactured in order to analyze and evaluate the impact of the quality of FGD gypsum on cement mortar when FGD gypsum is produced by the application of limestone sludge to the flue gas desulfurization process. In addition, the flow test of cement 


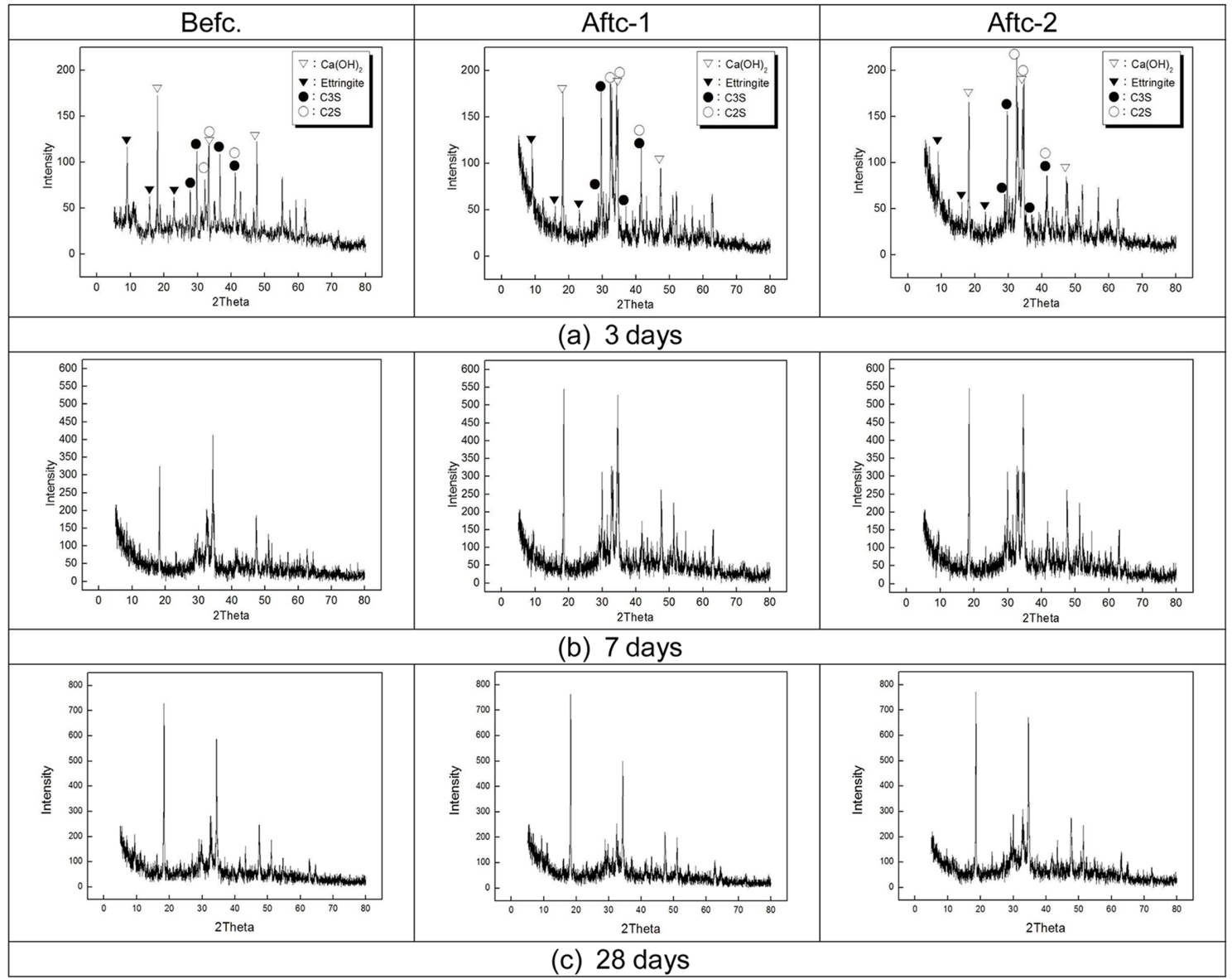

Fig. 3. XRD patterns of cement hydrate. (a) at 3 days cured cement paste fabricated with Befc., Aftc- 1 and Aftc-2. (b) at 7 days cured cement paste fabricated with Befc., Aftc-1 and Aftc-2. (c) at 28 days cured cement paste fabricated with Befc., Aftc1 and Aftc-2.

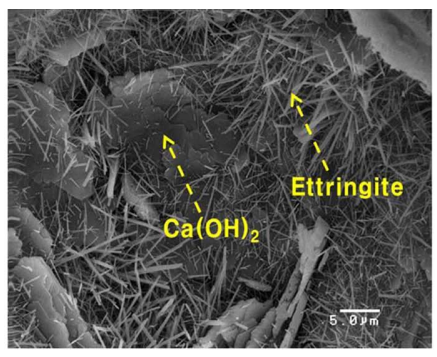

(a) Befc. (3 days)

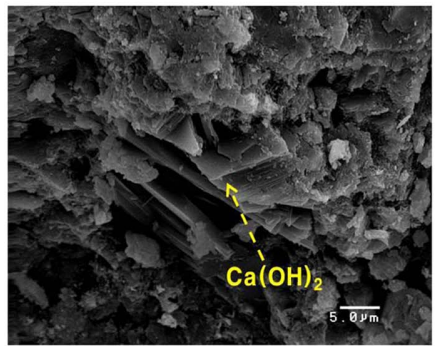

(d) Befc. (7 days)

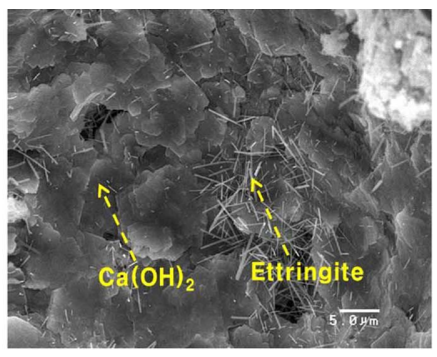

(b) Aftc-1 (3 days)

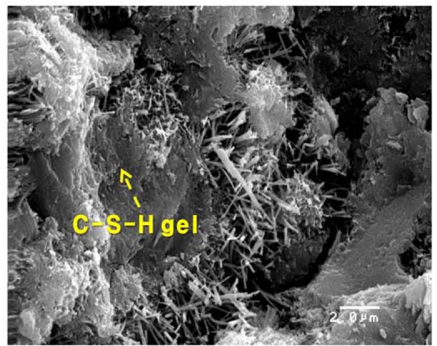

(e) Aftc-1 (7 days)

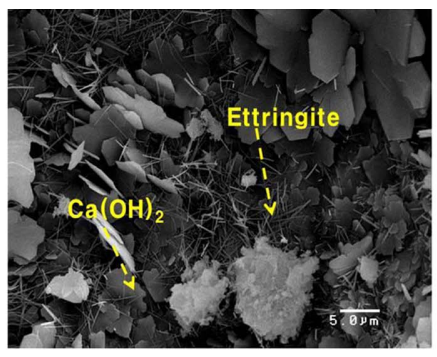

(c) Aftc-2 (3 days)

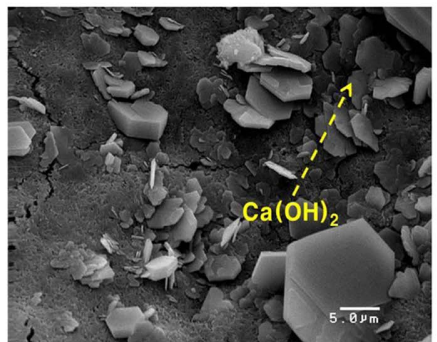

(f) Aftc-2 (28 days)

Fig. 4. Microstructure of cement hydrate (2kx) (a) at 3 days cured cement paste fabricated with Befc.. (b) at 3 days cured cement paste fabricated with Aftc-1. (c) at 3 days cured cement paste fabricated with Aftc-2. (d) at 7 days cured cement paste fabricated with Befc.. (e) at 7 days cured cement paste fabricated with Aftc-1. (f) at 28 days cured cement paste fabricated with Aftc-2. 
Table 3. Physical Properties of Cement

\begin{tabular}{ccccc}
\hline & \multirow{2}{*}{ Normal consistency (\%) } & \multicolumn{2}{c}{ Setting time } & \multirow{2}{*}{ Autoclave expansion (\%) } \\
\cline { 3 - 4 } & & Initial (min) & Final (hour:min) & 0.08 \\
Befc. & 23.8 & 130 & $2: 45$ & 0.10 \\
Aftc-1 & 23.7 & 130 & $2: 45$ & 0.09 \\
Aftc-2 & 23.8 & 135 & $2: 45$ & 0.00 \\
\hline
\end{tabular}

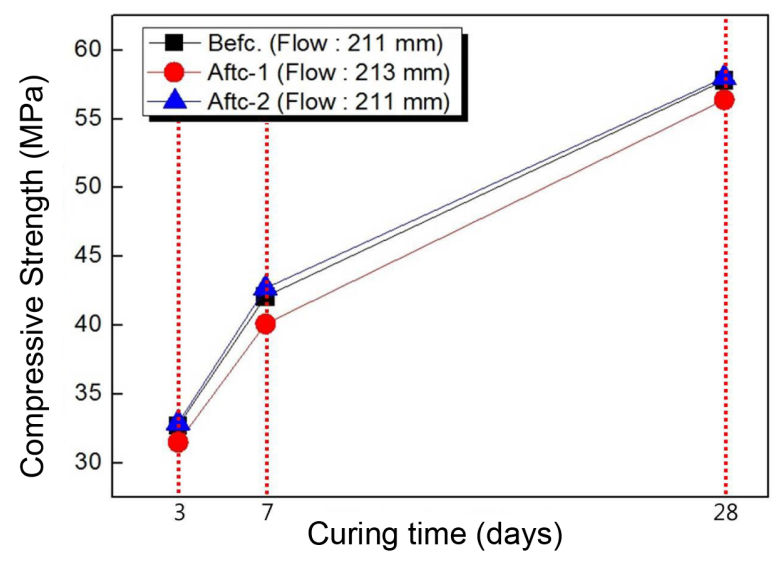

Fig. 5. Compressive strength and flow of mortar.

mortar was performed to evaluate the workability of cement mortar according to the type of FGD gypsum. Moreover, after prepared cement mortar specimens were water cured for 3 days, 7 days and 28 days in a constant temperature water bath with the temperature controlled to $21^{\circ} \mathrm{C}$, compressive strength according to the material age was measured, and the results are shown in Fig. 5.

Looking at the results of the measurement of the flow of cement mortar according to the type of FGD gypsum, the value of the specimen made from FGD gypsum produced before adding limestone sludge was $211 \mathrm{~mm}$, and the values of the specimens made from FGD gypsum produced after adding limestone sludge were $213 \mathrm{~mm}$ and $211 \mathrm{~mm}$, respectively. In other words, no significant differences in the workability of cement mortar according to the type of FGD gypsum were found. In addition, the results of the measurement of compressive strength according to the cement type showed that the compressive strength for the material age of 3 days was $31.5 \sim 32.9 \mathrm{MPa}$, and the compressive strengths for the material ages of 7 days and 28 days were $40.1 \sim$ $42.7 \mathrm{MPa}$ and $56.4 \sim 58.0 \mathrm{MPa}$, respectively. These results indicated that cement specimens had similar physical properties, as shown in the results of the experiments of physical properties of cement presented above, and they were thought to show that FGD gypsum produced using limestone sludge hardly had any effects on the physical properties of cement. In other words, the addition of limestone sludge was observed to have no significant influence on the quality of FGD gypsum.

\section{Conclusions}

Limestone sludge is applied as a desulfurizing agent in order to reduce the amount of limestone (desulfurizing agent) used to remove SOx gas in thermal power plants and reuse limestone sludge generated in steel mills. In this study, cement was manufactured using FGD gypsum and the physical properties of the cement were analyzed and evaluated in order to analyze and assess the quality of the FGD gypsum produced by the application of limestone sludge. The results were as follows:

Cement was manufactured using different types of FGD gypsum produced before and after the field application of limestone sludge, and the analysis of cement hydrates was performed. The results of the analysis of crystalline phases showed that ordinary Portland cement hydrates such as Ettringite, C-S-H based hydrates and $\mathrm{Ca}(\mathrm{OH})$ were generated in all the specimens which were different in the material age, and identical crystals were identified through the observation of the microstructure using a scanning electron microscope. In addition, similar results were obtained from all the specimens in the experiments on setting time and autoclave expansion using a Vicat apparatus and autoclave. In other words, when cement was made by using FGD gypsum manufactured from limestone sludge in the cement manufacture process, no significant differences in the physical properties of cement were observed, and these results were thought to show that the use of limestone sludge in the flue gas desulfurizatione process did not have any significant effects on the quality of FGD gypsum.

After cement was manufactured using FGD gypsum produced using limestone sludge, experiments for testing physical properties of cement mortar were performed, and the results showed that the values of all the specimens were similar in the test of the mortar flow; they ranged from 211 to $213 \mathrm{~mm}$. In addition, for compressive strength of mortar according to the material age, similar results were obtained from all the specimens; the measured value was 31.5 $32.9 \mathrm{MPa}$ for the specimen with the material age of 3 days, $40.1 \sim 42.7 \mathrm{MPa}$ for the one with the material age of 7 day, and 56.4 58.0 MPa for the one with the material age of 28 days.

The experimental results presented above indicated that FGD gypsum produced using limestone sludge had no effect on the physical properties of cement, and thus, it was believed that the application of lime sludge to the flue gas desulfurization process did not result in any significant differences in the quality of FGD gypsum. 


\section{REFERENCES}

1. N. W. Frank, G. A. Miller, and D. A. Reed, "Operating and Testing a Combined $\mathrm{SO}_{2}$ and NOx Removal Facility," Environ. Prog., 6 [3] 177-82 (1987).

2. M. D. Tu and S. G. Chang, "Chemistry of a Flue Gas Combined NOx and $\mathrm{SO}_{2}$ Scrubber Employing Ferrous Cysteine Additives," Environ. Prog., 6 [2] 51-6 (1987).

3. S. H. Kim, H. K. Lee, B. M. Min, and W. K. Choi, "Analysis of Flue Gas Desulfurization Technology," Energy R\&D, 64 [9] 143-59 (1993).

4. T. Pavel, D. Jaroslava, K. Jiri, R. Pavla, and C. Robert, "Flue Gas Desulfurization Gypsum: Study of Basic Mechanical, Hydric and Thermal Properties," Construction and Building Materials, 21 [1] 1500-9 (2007).
5. J. Warych and M. Szymanowski, "Optimum Values of Process Parameters of the Wet Limestone Flue Gas Desulfurization System," Chem. Eng. Technol., 25 [4] 4227-32 (2002).

6. H. S. Kim, "Necessity of Refining Domestic Limestone," $J$. Korean Inst. Resour. Recycl., 20 [4] 3-22 (2011).

7. S. K. Seo, Y. S. Chu, K. B. Shim, J. K. Lee, H. Song, and Y. M. Yun, "A Study on the Application with Limestone Sludge at Flue Gas Desulfurization Process," J. Korean Ceram. Soc., 51 [6] 573-83 (2014).

8. Z. G. Tang, C. C. Zhou, and C. Chen, "Studies on Flue Gas Desulfurization by Chemical absorption Using and Ethylenediamine-Phosphoric Acid Solution," Ind. Eng. Chem. Res., 43 [21] 6714-22 (2004). 